Dhaka Univ. J. Biol. Sci. 23(2): 109-117, 2014 (July)

\title{
BIOLOGY OF COMMON ROSE BUTTERFLY, PACHLIOPTA ARISTOLOCHIAE FABRICIUS (LEPIDOPTERA: PAPILIONIDAE) ON THE HOST PLANT, ARISTOLOCHIA INDICA L. (ARISTOLOCHIACEAE)
}

\author{
Md. Maksudul Alam, M.A. Bashar and Humayun Reza Khan \\ Department of Zoology, University of Dhaka, Dhaka-1000, Bangladesh
}

Key words: Biology, Common rose butterfly, Feeding potential, Instar, Incubation

\begin{abstract}
To study the biology of Pachliopta aristolochiae on its host plant Aristolochia indica singly laid eggs on the host plant were collected from the field and reared in the laboratory under optimum conditions of temperature $\left(28 \pm 3{ }^{\circ} \mathrm{C}\right)$ and relative humidity $(70 \pm 5 \% \mathrm{RH})$. Incubation period of the egg was $5.0 \pm 0.6$ days, larval developmental period was $11 \pm 0.3$ days, pre-pupal period was $0.87 \pm 0.08$ day, and the pupation took $12 \pm 0.63$ days. The length of $1^{\text {st }}, 2^{\text {nd }}, 3^{\text {rd }}$ and $4^{\text {th }}$ instar larvae were $4.0 \pm 0.63,9 \pm 0.63,22.6 \pm 5.2$ and $38.2 \pm 4.70 \mathrm{~mm}$, respectively. The feeding potential rate of $1^{\text {st }}, 2^{\text {nd }}, 3^{\text {rd }}$ and $4^{\text {th }}$ instar larvae were $11.4 \pm 5.04,29.6 \pm$ $5.12,51.4 \pm 6.0$ and $72.8 \pm 4.9 \%$, respectively. The weight of the faeces of $1^{\text {st }}, 2^{\text {nd }}, 3^{\text {rd }}$ and $4^{\text {th }}$ instar larvae were $0.012 \pm 0.004,0.047 \pm 0.018,0.0114 \pm 0.023$ and $0.274 \pm$ $0.045 \mathrm{gm}$, respectively.
\end{abstract}

\section{Introduction}

All butterflies are herbivores in their larval stages, majority of them are host specific and have close relationship with their host plants ${ }^{(1)}$. The common rose butterfly, Pachliopta aristolochiae (Lepidoptera:Papilionidae) is a swallow tail butterfly. It is a common butterfly and abundant across South and South East Asia(2). The IUCN status of this species is 'very common' and 'not threatened' in the Indo-Burma hotspot (3). The identifying field characters of this butterfly are a sub-marginal row of red lunular markings and a discal row of white spots on upper side of hind wings. The hind wings also bear robust club shaped black tails. The wingspan is $80-110 \mathrm{~mm}^{(4)}$. The larval food plant Aristolochia indica and A. tagala are poisonous creepers (vine) belonging to family Aristolochiaceae which are also mostly tropical(6). Commonly known as the Indian Birthwort (Local name: Iswarimul) which has pharmacological properties ${ }^{(7)}$ and the plant extract is known to have potent anti cancer properties ${ }^{(8)}$. Butterflies select host plants for oviposition using chemical cues. Females usually oviposit only on those plants, which are suitable for larval growth and survival. They usually select new larval food plants, which are related to their usual host plants ${ }^{(9)}$. The larval stages of all the red-bodied swallow tails are Aristolochia feeders and this makes them unpalatable to their vertebrate enemies like birds and reptiles due to the sequestering of aristolochic acids in the larval tissues 
which are passed on to the adults ${ }^{(5,10)}$. The present experiment was carried out on the biology of common rose butterfly, emphasizing on the larval activities with the change of time. This theme was undertaken with a view to analyzing the association between butterfly and plant that could be utilized as a tool for the effective biodiversity conservation management through butterfly colonization process.

\section{Materials and Methods}

The biology of Pachliopta aristolochiae was studied in the Environmental Biology and Biodiversity Laboratory, Department of Zoology, University of Dhaka for two consecutive years from 2008 to 2009 during the monsoon season under optimum conditions of temperature $\left(28 \pm 3^{\circ} \mathrm{C}\right)$ and relative humidity $(70 \pm 5 \%)$.

The egg laying of the adult female was studied in the field on its host plant. The larvae were reared in three-layered plastic cage in which two pieces of cork-sheets were attached to $1^{\text {st }}$ layer for creating space between $2^{\text {nd }}$ and $3^{\text {rd }}$ layers. The collected young leaves were put in $2^{\text {nd }}$ layer for rearing the larvae. The $3^{\text {rd }}$ layer was used to cover the $2^{\text {nd }}$ layer. The space between $2^{\text {nd }}$ and $3^{\text {rd }}$ layers was used to make aeration for the larvae. The life stages of $P$. aristolochiae were studied following the methods of Rafi et al.(11).

For studying the feeding potential rate of larvae, ten fresh and young leaves were provided to the larvae for their development through various stages within $24 \mathrm{hrs}$ of intervals. After supplying the young leaves, water was sprayed on the leaves to prevent from desiccation and to achieve the turgidity of the leaves for long time. The feeding potential rates of the larvae were calculated by counting the number of leaves by using the following formula:

TLSA $=l_{1}+l_{2}+\ldots \ldots \ldots \ldots \ldots \ldots+l_{n}$

where, TLSA $=$ Total leaves of surface area per $24 \mathrm{hrs,}$

$l_{1}=$ Single leaf of surface area $=10 \%$ (was supposed),

$l_{2}=$ Double leaves of surface area $=20 \%$ and

$l_{n}=n$ number leaves of surface area $=10$ leaves $($ constant $)=100 \%$ (provided per 24 hrs).

The larval excreta were weighed after every $24 \mathrm{hrs}$. After hatching the larval length, morphological characters, larval feeding potential rate and larval excreta were observed and recorded in $24 \mathrm{hrs}$ intervals following Barua and Slowik ${ }^{(12)}$. The experiments were repeated ten times for all life stages on the host plants in laboratory.

\section{Results and Discussion}

Adult female of rose butterfly has been observed inspecting Aristolochiae plants and selecting healthy plants with verdant growth to ensure adequacy of food for its voracious caterpillars. It lays round reddish eggs with fine black markings (Fig. 1a). The eggs were 
laid singly on top, the underside of leaves or even on shoots. Each egg measured 1 - 2 $\mathrm{mm}$ in diameter and was brick red at the top while the remaining portion was dark orange in colour. They were round in shape but flattened at the bottom surface, which

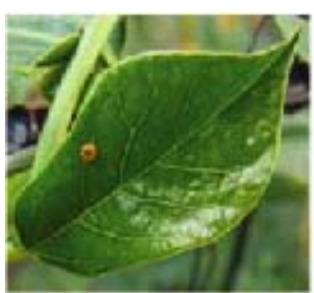

(a) Egg<smiles>C1=CCCC1</smiles>

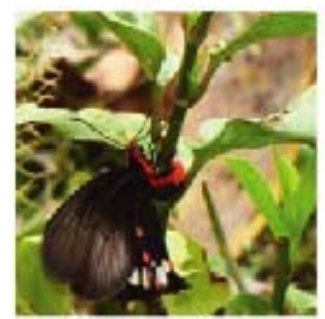

(j) Egg-laying

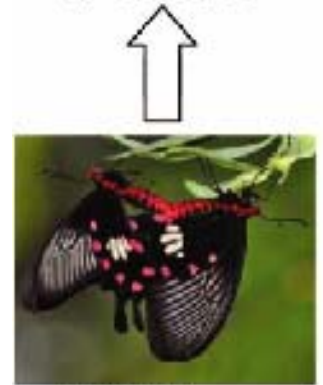

(i) Mating

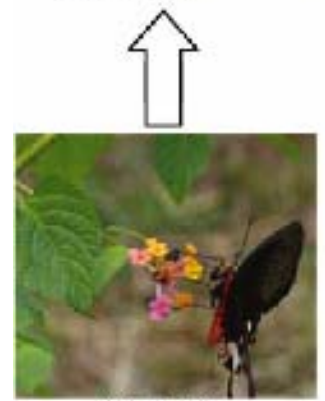

(h) Adult

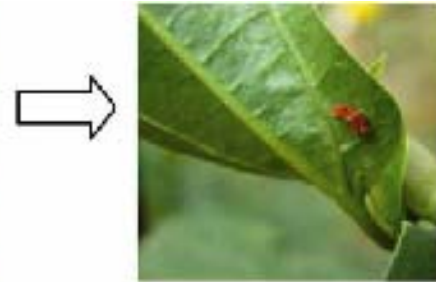

(b) 1st instar larva

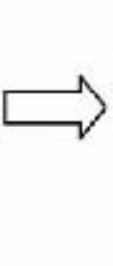

(c) 2nd instar larva

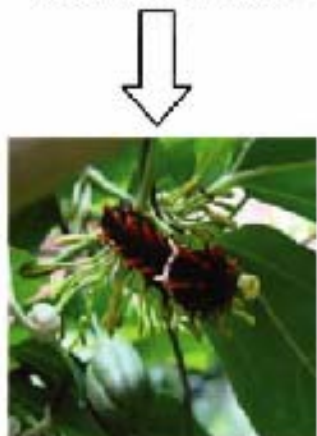

(d) 3rd instar larva

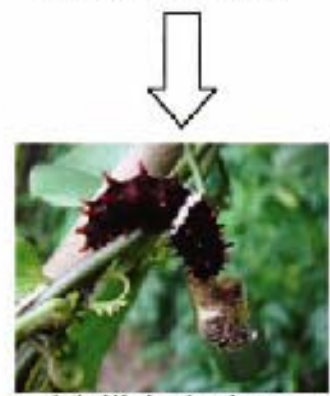

(e) 4th instar larva

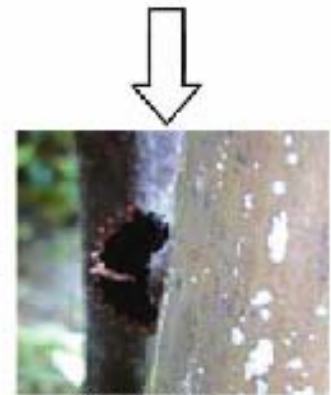

(f) Pre-pupa

Fig. 1(a - j). The life cycle of common rose butterfly, Pachliopta aristolochiae on the host plant, Aristolochia indica. 
was found attached to the leaf or stem. In field conditions it was observed that a gravid female laid 8 - 10 eggs at a time on different leaves of the host plant and within a time span of $5 \mathrm{~min}$. The females were observed to repeatedly visit the host plants and tried to probe the leaves for ascertaining their suitability for egg laying like the tender nature of the leaves and availability of shade. After repeatedly flying around the host plant for about 5 - $8 \mathrm{~min}$, a female was observed to lay one egg in each of the tender leaves. During egg laying, the forewings were observed to be continuously fluttering and it took about 5 sec to lay a single egg. The female under observation laid only two eggs within a time span of $30 \mathrm{sec}$. The female repeatedly tested similar-shaped leaves before finally selecting the underside of suitable tender leaves in a shady damp place for egg laying. Similar behavior was reported by Stamp ${ }^{(13)}$ and Davies and Gilbert ${ }^{(14)}$. In the laboratory, it was observed that just 5 - 10 min before hatching, the apical portion of the egg became dark brown in colour while the remaining portion of the egg was bright yellow. This species was observed to lay the eggs singly as was the case with most papilionid butterfly species(15). The single egg-laying habit has an advantage in that it averts the possibilities of larval saturation by resource exhaustion and enables effective utilization of isolated plants $^{(16)}$. In the absence of suitable tender leaves, the female preferred to oviposit on tender shoots. The incubation period was found as $5 \pm 0.6$ days (Table 1 ).

The 1st instar larvae slowly emerged by splitting open the egg case at the apical tip. The time taken for hatching was 25 - $30 \mathrm{~min}$. The freshly emerged larvae started feeding on the yellow coloured empty egg case after about $10 \mathrm{~min}$. The larvae were very sluggish in movement. They defoliated the early tender leaves by making small irregular shaped holes. The feeding time was recorded as $1-2 \mathrm{~min}$ followed by a resting period of $80-100$ min. The freshly emerged larvae are transparent pale red in colour with faint blackish markings on the body. The body was covered with minute pale yellowish fleshy spines (Fig. 1b). The larvae started feeding on the egg case $10 \mathrm{~min}$ after hatching and it was observed that after about $40 \mathrm{~min}$ the body colour of the larvae changed to pale brown. The larvae took rest on the underside the leaves of the host plant ${ }^{(9)}$. This larval duration was found to be $1.5 \pm 0.3$ days (Table 1 ).

The 2nd instar larvae also preferred to feed on the tender leaves and defoliated along the sides of the leaf margin. The feeding duration was 2 - 3 min followed by a resting period of 1 - 2 hrs. While feeding the larvae defoliated the leaves from the lower side and therefore remained least exposed to their predators. The larval colour was brownish black bearing 12 pairs of fleshy spines on both dorsal and lateral sides (Fig. 1c). The first 5 pairs of dorsal spines were brownish red in colour, the 6th pair creamy white and the last 6 pairs of abdominal spines were again brownish red in colour. The first 5 pairs of lateral fleshy spines were, however, brownish black in colour. The dorsal spines were longer than the lateral ones, each measuring $2 \mathrm{~mm}$ in length. In the 6th segment, the paired dorsal and lateral spines are joined on each side by a white line. As the larval life 
progressed, it grew bigger with the fleshy spines becoming more prominent ${ }^{(15)}$. The larvae took rest on the lower surface of the leaves and larval duration was found to be 2.5 \pm 0.3 days (Table 1 ).

Table 1. Developmental stages of the common rose butterfly, Pachliopta aristolochiae.

\begin{tabular}{lc}
\hline Stages & Duration in days $($ Mean \pm Sd $)$ \\
\hline Incubation & $5.0 \pm 0.6$ \\
$1^{\text {st }}$ instar & $1.5 \pm 0.3$ \\
$2^{\text {nd }}$ & $2.5 \pm 0.3$ \\
$3^{\text {rd }}$ & $3.0 \pm 0.3$ \\
$4^{\text {th }}$ & $4.0 \pm 0.3$ \\
Pre-pupa & $0.87 \pm 0.08$ \\
Pupa & $12 \pm 0.63$ \\
\hline
\end{tabular}

The mature $3^{\text {rd }}$ instar larvae were voracious feeders, which defoliated tender, young and matured leaves. The feeding time was recorded as $10-12 \mathrm{~min}$ followed by a resting period of $45 \mathrm{~min}$ to $1 \mathrm{hr}$. The larvae preferred to take rest on the underside of leaves. Body was velvety black and covered with 12 pairs of fleshy spines. The dorsal spines were brick red while the lateral spines were black with red tips (Fig. 1d). Each dorsal spine measured $2 \mathrm{~mm}$ and each lateral spine measured $1 \mathrm{~mm}$ in length. The 6th pair of dorsal and lateral spines were reddish white and joined on both sides by a pair of reddish white lateral lines. Also in the 6th segment, a white line measuring $1 \mathrm{~mm}$ in thickness joined the brick red dorsal spines on the upper side. As the larval stage progressed, it was observed that a small oval shaped black marking appeared on the lateral white lines of both sides. The first three anterior segments carried an additional pair of pale red fleshy spines between the dorsal and lateral spines. In the absence of suitable leaves, they were also observed to feed on the tender shoots and flowers of the host plant $(9,15)$. Larval duration was recorded as $3 \pm 0.3$ days (Table 1 ).

The robust $4^{\text {th }}$ instar larvae were also found to be voracious feeders, which preferred to defoliate the mature leaves. The feeding time recorded was $20-25$ min which was followed by a resting period of $1-2$ hrs. When disturbed they ejected out a pair of orange-coloured osmateria and quickly moved away to a different site. The larvae has a dark velvety black body and the fleshy spines were crimson red in colour at the upper portion and black at the basal half. The dorsal and lateral spines on the 6th segment were creamish white in colour and were joined both dorsally and laterally by thick white lines. Oval shaped black markings are prominently present in the middle of the white lines on both the lateral sides. Just after moulting, the 6th segment fleshy spines became pale orange in colour, which gradually faded with a mild orange tinge at their free apical tips. 
First three anterior segments bears an additional pair of pale red fleshy spines (Fig. 1e). All the spines gradually become more prominent with increasing thickness. In the absence of suitable leaves larvae were found to consume both young and mature shoots as well as fruits of the host plant ${ }^{(9,15)}$. Larval duration was found to be $4 \pm 0.3$ days (Table 1).

Pre-pupal and pupal duration were found to be $0.87 \pm 0.08$ and $12.0 \pm 0.63$ days, respectively (Table 1). According to Barua and Slowik, (12) the laboratory study revealed an incubation period of \pm 4 days, larval duration of \pm 20 days, and pupation period of \pm 12 days. Time duration varies due to the environmental factors, species variation of the host plant and availability of the larval food sources ${ }^{(14)}$.

The length of $1^{\text {st }}, 2^{\text {nd }}, 3^{\text {rd }}$ and $4^{\text {th }}$ instar were $4.0 \pm 0.63,9.0 \pm 0.63,22.6 \pm 5.2$ and $38.2 \pm$ $4.70 \mathrm{~mm}$, respectively (Table 2). The larval size depends on the availability of food sources. The $4^{\text {th }}$ instar larva quickly metamorphosed into pre-pupa when foods were not available to them. In this condition, the larvae could not make pupal covering (cocoon) properly and took a longer time than required and the emergence rate of adult from pupa was poor. The size of larval instar was also reduced in such condition. Barua and Slowik ${ }^{(12)}$ reported that the average length of these larval instars of P. aristolochiae as 4.0, 7.5, 19.0 and $35.0 \mathrm{~mm}$, respectively on its host plant, A. tagala in laboratory condition. Environmental factors, moderate supply of larval food and different host plants caused the variation of larval length(14).

Table 2. The variation in length, feeding potential and faeces (excreta) of larvae of the common rose butterfly, $P$. aristolochiae.

\begin{tabular}{lccc}
\hline Larva & $\begin{array}{r}\text { Length }(\mathrm{mm}) \\
(\text { Mean } \pm \mathrm{Sd})\end{array}$ & $\begin{array}{c}\text { Feeding potential rate } \\
\text { in \% }(\text { Mean } \pm \mathrm{Sd})\end{array}$ & $\begin{array}{c}\text { Faeces }(\mathrm{gm}) \\
(\text { Mean } \pm \mathrm{Sd})\end{array}$ \\
\hline $1^{\text {st }}$ instar & $4.0 \pm 0.63$ & $11.4 \pm 5.04$ & $0.012 \pm 0.004$ \\
$2^{\text {nd }}$ " & $9.0 \pm 0.63$ & $29.6 \pm 5.12$ & $0.047 \pm 0.018$ \\
$3^{\text {rd }}$ & $22.6 \pm 5.2$ & $51.4 \pm 6.0$ & $0.0114 \pm 0.023$ \\
$4^{\text {th }}$ & $38.2 \pm 4.70$ & $72.8 \pm 4.9$ & $0.274 \pm 0.045$ \\
\hline
\end{tabular}

The feeding potential rate of $1^{\text {st }}, 2^{\text {nd }}, 3^{\text {rd }}$ and $4^{\text {th }}$ instar larvae were found to be $11.4 \pm$ $5.04,29.6 \pm 5.12,51.4 \pm 6.0$ and $72.8 \pm 4.9 \%$, respectively (Table 2 ). The $1^{\text {st }}$ and $2^{\text {nd }}$ instar larvae usually prefer to feed on tender parts of $A$. indica. The $3^{\text {rd }}$ and $4^{\text {th }}$ instar usually prefer to feed on young and mature leaves. Feeding potential of $1^{\text {st }}$ and $2^{\text {nd }}$ instar larvae were very less than $3^{\text {rd }}$ and $4^{\text {th }}$ instar larvae ${ }^{(12)}$. Later instar larvae become voracious feeder to store more nutrients. More energy was required to be metamorphosed into pupa and that is why $90-100 \%$ supplied leaves were consumed by later instar larvae ${ }^{(14)}$.

The weight of faeces of $1^{\text {st }}, 2^{\text {nd }}, 3^{\text {rd }}$ and $4^{\text {th }}$ instar larvae were $0.012 \pm 0.004,0.047 \pm$ $0.018,0.0114 \pm 0.023$ and $0.274 \pm 0.045 \mathrm{gm}$, respectively (Table 2 ). The excretory product of 
larvae was proportionate to the feeding potential rate of larvae. It was measured that the excretory products of $1^{\text {st }}$ and $2^{\text {nd }}$ instar larvae were less compared to $3^{\text {rd }}$ and $4^{\text {th }}$, because the feeding potential rate of $3^{\text {rd }}$ and $4^{\text {th }}$ instar larvae were more compared to $1^{\text {st }}$ and $2^{\text {nd }}$. It was found that before pre-pupation, $4^{\text {th }}$ instar larvae usually excreted very large sized droppings and more amount than previous instars. Larval faeces were in liquid form primarily at hatching but become solid after 2 - 3 days.

Fourth instar larva became shorten to form the pre-pupa and feeding was stopped. Gradually it formed arch shaped and thread like structures through which are attached hard supporting to be modified into pupa. The length of pre-pupa was $20-25 \mathrm{~mm}$. Prepupal duration was found as $0.87 \pm 0.21$ day (Table 1 ).

The entire process of pupation completed within 14 - 15 hrs. In the field condition, pupation took place among dense, low-growing vegetation and this has conformity with the records of Vane-Wright and Ackery ${ }^{(15)}$. The pupa was brownish with various shades of brown and pink markings. It was attached to the twig on stick by the tail and held at an angle by a body band (Fig. 1g). The distinguishing feature of the pupa was the presence of large semi-circular projections on the back of the abdomen, thorax and head. It was light brown in colour with a mixture of white, orange and dark brown pattern markings on the dorsal side. The ventral side was light brown with faint white stripes. The anterior end of the chrysalis was produced into a frontally flattened broad projection, which further has a pair of flattened flaps on either lateral side. The 2nd pair of dorso-ventrally flattened flaps was present in the mid-anterior region. Between these two pairs there, was a pair of markings having a mixture of white and dark brown colouration. Just below these markings, mid-dorsally the anterior part was raised into a pair of light brown continuous frilly flaps. The wing case bear two pairs of dorsoventrally flattened, light brown flaps which further possessed on their upper side, some patterned markings having a mixture of white, orange and dark brown colouration. These are also described by Haribal ${ }^{(4)}$, Vane-Wright and Ackery ${ }^{(15)}$. There are four segments in the posterior part of the wing case and each segment has one pair of laterally flattened light brown flaps. The chimaster was black in colour and was seen around the fourth anterior segment. The pupal size was recorded as $25 \times 15 \mathrm{~mm}$ and the period was $12 \pm 0.63$ days (Table 1 ).

The extended tail of the hind wings were found to be comparatively pointed in females and more or less rounded in males. The upper side of male was velvety black (Fig. 1h). Fore wing with well-marked pale adnervular streaks on the discal area that did not reach the terminal margin, the latter broadly velvety black; the streaks beyond end of cell extended inwards into its apex. Hind wing with elongate white discal markings. In females, the abdomen was seen distinctly larger than that of the males as described by Collins and Morris(3). The inner margin of the hind wings had tufts of hair in the males, which are actually the scent scales from where the pheromones were released during the 
time of mate selection ${ }^{(16)}$. Haribal ${ }^{(4)}$ reported that the total life cycle of $P$. aristolochiae was completed within \pm 30 days in laboratory conditions. In the field study it was found that the common rose completed $7-8$ generations in a year. The first generation emerged in March - April and the last generation was completed in December.

In the field, the females were observed to lay eggs on the tender shoots and leaves of the host plant. A single female was observed to lay an average of 6 - 8 eggs in a sequence and preferably on different tender leaves. The biology of $P$. aristolochiae with respect to egg-laying and larval development was dependant on the host plants $A$. indica and $A$. tagala. The food plant resources of $P$. aristolochiae in the field showed that it utilized nearly 10 - 12 species of flowering shrubs and trees for harvesting nectar and species, of them Lantana camara, Hibiscus rosasinensis, Adina codifolia, Duranta repens and Clerodendrum infortunatum were observed in year long flowering condition. To conserve the common rose butterfly, the host-plants and nectar plants of this species must be protected and conserved in nature ${ }^{(17)}$. A sustainable harvest of this red-bodied swallow tail in butterfly breeding houses will not only help in maintaining the recovering populations in the wild but the dead stock having good commercial trade value will also contribute to the trade in butterflies. Captive breeding will also help in a better understanding of its biology and an effective conservation strategy through creation of local awareness, particularly amongst the school children and local villagers living near protected and unprotected forests, can prove to be the most effective method for conservation of butterflies.

\section{Acknowledgement}

The authors gratefully acknowledge the financial support by the Ministry of Science and Technology, Government of the People's Republic of Bangladesh for conducting this research.

\section{References}

1. Price PW, GW Fernands, TM Lewinsohn and WW Benson 1991. Plant-Animal Interactions. John Willey \& Sons Inc. pp. 39.

2. Wynter-Blyth MA 1957. Butterflies of the Indian Region. Bombay Natural History Society, Bombay.

3. Collins NM and MG Morris 1985. Threatened Swallowtail Butterflies of the World. The IUCN Red Data Book, Gland and Cambridge. pp. 40.

4. Haribal M 1992. Butterflies of Sikkim Himalaya and their Natural History. Publs. Sikkim Nature Conservation Foundation (SNCF), Sikkim. pp. 65.

5. Von Euw J, T Reichstein and M Rothschild 1968. Aristolochic acid-I in the swallow tail butterfly Pachliopta aristolochiae (FABR.) (Papilionidae). Israel J. Chem. 6: 659-670.

6. Hoehne FC 1942. Aristoloquiaccas. Flora Brasilica 15: 3-141. 
7. Chen ZL and DY Zhu 1987. Aristolochia alkaloids. Chemistry and Pharmacology 31: 29-65.

8. Hynniewta TM and KA Baishya 1992. Floristic Wealth of Northeast India. Zoological Society of Assam, Guwahati, India.

9. Kunte K 2006. Additions to known larval host plants of Indian butterflies. J. Bombay Nat. Hist. Soc. 103(1): 119-120.

10. Rausher MD and P Feeny 1980. Herbivory, plant density and plant reproductive success the effects of Battus philenor on Aristolochia reticulate. Ecology 61: 905-917.

11. Rafi MA, MR Khan and MA Matin 1999c. Biology of eggs of citrus butterfly, Papilio demoleus L. (Papilionidae: Lepidoptera). Pakistan J. Sci. 51 (3-4): 95-99.

12. Barua KK and J Slowik 2007. Study on the biology and consumption potential of Common Rose, Pachliopta aristolochiae aristolochiae F (Lepidoptera Papilionidae) on Aristolochia tagala. Polish J. Ent. 76: 341-352.

13. Stamp NE 1980. Egg deposition patterns in butterflies: Why do some species cluster their eggs rather than deposit them singly? Amer. Nat. 115: 367-380.

14. Davies CR and N Gilbert 1985. A comparative study of the egg-laying behaviour and larval development of Pieris rapae L. and P. brassicae L. on the same host plants. Oecologica 67: 278-281.

15. Vane-Wright RI and PR Ackery 1984. The Biology of Butterflies. Academic press, London. pp. 220.

16. Kemp DJ 2002b. Sexual selection constrained by life history in a butterfly. Proc. R. Soc. B. 269 : 1341-1345.

17. Wiklund C and C Ahrberg 1978. Host plants, nectar source plants and habitat selection of males and females of Anthocharis cardamines (Lepidoptera). Oikos 31: 169-183.

(Manuscript received on 21 April, 2014; revised on 30 June, 2014) 